\title{
A IGREJA CATÓLICA \\ E OS SUJEITOS NEGROS \\ DO CICLO DO MARABAIXO: \\ UMA MAQUINARIA \\ DISCURSIVA OPERANDO \\ PRÁTICAS CONFLITANTES ${ }^{1}$
}

\section{LA IGLESIA CATÓLICA Y LOS SUJETOS NEGROS DEL CICLO DE MARABAIXO: UNA MAQUINARIA DISCURSIVA QUE OPERA PRÁCTICAS CONFLICTIVAS}

\section{THE CATHOLIC CHURCH AND THE BLACK SUBJECTS OF THE CICLO DO MARABAIXO: A DISCURSIVE MACHINERY OPERATING CONFLICTING PRACTICES}

Ednaldo Tartaglia*

Universidade Federal do Amapá

RESUMO: O presente texto trata do funcionamento do dispositivo religioso cristão em práticas conflitantes entre a Igreja Católica e os sujeitos negros do Marabaixo urbano de Macapá. As materialidades sobre as quais nos debruçamos são constituídas por ditos e escritos acerca das práticas dos sujeitos do Marabaixo, entre o século XIX e XXI (textos jornalísticos impressos e televisivos, documentários, livros, blogs etc.). Elegemos como suporte teórico e metodológico a Análise do Discursivo de linha foucaultiana e trabalhamos sob a ótica do dispositivo (FOUCAULT, 1977; DELEUZE, 1990; AGAMBEN, 2005; VEYNE, 2011). A análise sinaliza o funcionamento de uma maquinaria discursiva que, ao mesmo tempo em que construiu, também deslegitimou os sujeitos negros do Marabaixo urbano de Macapá.

PALAVRAS-CHAVE: Discursos. Dispositivo. Poder. Sujeito negro do Marabaixo.

RESUMEN: Este texto trata del funcionamiento del dispositivo religioso cristiano en prácticas conflictivas entre la Iglesia Católica y los sujetos negros del Marabaixo urbano de Macapá. Las materialidades en las que nos centramos están constituidas por dichos y escritos acerca de las prácticas de los sujetos de Marabaixo, entre los siglos XIX y XXI (textos periodísticos impresos y televisivos,

\footnotetext{
${ }^{1}$ Este trabalho consiste em um recorte de nossa tese de doutorado intitulada "Práticas de poder, de resistência e de subjetivação: os discursos dos/sobre os sujeitos negros do Ciclo do Marabaixo macapaense" e orientada pelo Professor Doutor Pedro Navarro do Programa de Pós-Graduação em Letras da Universidade Estadual de Maringá - PLE/UEM, bem como se inscreve em nosso atual projeto de pesquisa denominado "Negritude Amazônica: os sujeitos negros em discurso". 
documentales, libros, blogs, etc.). Elegimos como soporte teórico y metodológico el Análisis del Discurso foucaultiano y trabajamos bajo la perspectiva del dispositivo (FOUCAULT, 1977; DELEUZE, 1990; AGAMBEN, 2005; VEYNE, 2011). El análisis señala el funcionamiento de una maquinaria discursiva que, al mismo tiempo en que se construyó, también deslegitimó a los sujetos negros del Marabaixo urbano de Macapá.

PALABRAS CLAVE: Discursos. Dispositivo. Poder. Sujeto negro del Marabaixo.

ABSTRACT: This text deals with the functioning of the Christian religious device in conflicting practices between the Catholic Church and the black subjects of the urban Marabaixo of Macapá. The materialities that we focus on are constituted by sayings and writings about the practices of the subjects of Marabaixo, between the 19th and 21st century (printed and television journalistic texts, documentaries, books, blogs etc.). We chose as theoretical and methodological support the Foucaultian Discursive Analysis and worked from the device perspective (FOUCAULT, 1977; DELEUZE, 1990; AGAMBEN, 2005; VEYNE, 2011). The analysis signals the functioning of a discursive machinery that, at the same time as it built, also delegitimized the black subjects of the urban Marabaixo of Macapá.

KEYWORDS: Discourses. Device. Power. Black subject of the marabaixo.

\section{INTRODUÇ̃̃O}

Ciclo do Marabaixo, ou Marabaixo, é um conjunto de práticas festivas e religiosas de negros ligado ao calendário ritualístico católico. Ele acontece há mais de 260 anos no estado do Amapá. O Marabaixo se constitui pelo atravessamento de elementos da cultura africana, como a música, a dança, as vestimentas, as bebidas etc., vinculados a períodos litúrgicos da Igreja Católica. Pontuamos que o Ciclo do Marabaixo reúne elementos do catolicismo e de religiões africanas, porém, sinalizamos que não existe uma sobreposição dos santos católicos por orixás dos cultos afros, isto é, um sincretismo religioso. As festividades são em devoção aos santos da Igreja Católica. Entretanto, por ser constituído por elementos de matrizes africanas, o Ciclo foi mecanismo de atrito entre a Igreja, a comunidade local e os sujeitos negros praticantes do Marabaixo, ao longo de três séculos.

O Marabaixo acontece nas principais cidades do estado, como Mazagão, Santana e Macapá, seja nos perímetros urbanos, como também nas zonas rurais, comunidades quilombolas e ribeirinhas. Cada localidade dedica a festa ao santo de sua devoção. Em Macapá, esses festejos são em devoção à Santíssima Trindade e ao Divino Espírito Santo e são realizados, todos os anos, após o período litúrgico da Quaresma, passando pela Semana Santa e se estendendo até o Domingo do Senhor, que corresponde ao primeiro domingo após o feriado de Corpus Christi. Por isso, em Macapá, o Marabaixo é chamado de Ciclo, por se estender por aproximadamente sessenta dias, seguindo o calendário católico.

Feitos esses esclarecimentos, neste trabalho procuramos colocar em visibilidade o funcionamento do dispositivo religioso cristão operado nos atritos entre Igreja Católica e sujeitos negros do Marabaixo. Para isso, tomamos como base teórica e metodológica a Análise do Discurso de cunho foucaultiano e elegemos materialidades diversificadas que circularam entre os séculos XIX e XXI (texto de jornais, de blogs, de artigos científicos, de documentários e de matérias televisivas, de cantigas populares etc.) para analisar os discursos que ora objetivam, ora deslegitimam os sujeitos negros.

Na sequência, discutimos acerca do termo conceitual dispositivo e, posteriormente, observamos a maquinaria discursiva agenciada pelo dispositivo religioso cristão que funcionou no processo de silenciamento das práticas dos sujeitos negros do Ciclo do Marabaixo. Em outra direção da análise, destacamos o exercício de resistências dos sujeitos negros às práticas opressoras da Igreja.

\section{CIRCUNSCREVENDO UM DISPOSITIVO RELIGIOSO CRISTÃO}

Nesta seção, trataremos da noção de dispositivo advinda da teoria foucaultiana, pois ela possibilitará compreender como emergiram e funcionam as ações e as práticas discursivas maquinadas pelos sujeitos negros do Marabaixo e pela Igreja. Ao discutir o dispositivo,

Tartaglia | A igrejacatólica e os sujeitos negros do ciclo do Marabaixo.. 
delimitaremos o que vem a ser o dispositivo religioso cristão que, a nosso ver, operou nos diversos conflitos travados entre os sujeitos negros do Ciclo do Marabaixo e a Igreja Católica em Macapá, no estado do Amapá.

Agamben (2005) salienta que o dispositivo é um elemento central no pensamento foucaultiano. Segundo ele, Foucault teria buscado o termo "positividade" nos trabalhos de seu mestre, Hyppolite, a respeito de Hegel. Hyppolite discutiu a oposição entre natureza e positividade. Já Hegel procurou relacionar a razão (natureza) com a história (positividade). Assim, em seus estudos, Foucault procurou verificar a relação entre os indivíduos e seres históricos, ou seja, os indivíduos constituídos em sujeitos. Em outras palavras, Foucault estudou "[...] os modos concretos em que as positividades [ou os dispositivos] atuam nas relações, nos mecanismos e nos 'jogos' de poder” (AGAMBEN, 2005, p. 11).

Assim, Foucault (1977, p. 62-3, tradução nossa) traz, no texto Le jeu de Michel Foucault ${ }^{2}$, o qual está na versão francesa de Ditos e escritos III, a seguinte definição para o termo dispositivo:

[...] é, em primeiro lugar, um conjunto decididamente heterogêneo, incluindo os discursos, instituições, arranjos arquitetônicos, decisões regulamentares, leis, medidas administrativas, enunciados científicos, propostas filosóficas, de moral, filantrópicas [...]. O próprio dispositivo é a rede que se estabelece entre elas. [...] Em segundo lugar, gostaria de identificar que o dispositivo é precisamente a natureza da relação que pode existir entre esses elementos heterogêneos. [...] Em suma, entre estes elementos, discursivos ou não, há um jogo de mudanças de posição, mudanças nas funções, que também pode ser muito diferente. [...] Em terceiro lugar, entendo por dispositivo uma espécie - digamos - de formação que, em algum momento, teve a função principal de responder a uma emergência. Por conseguinte, o dispositivo tem uma função estratégica dominante.

Com essa citação, podemos compreender o dispositivo como uma maquinaria composta por elementos heterogêneos os quais mantêm uma correlação, isto é, funcionam como redes e estão sempre associados a uma relação de poder. Essa relação de poder encadeada através das redes, que podem ser linguísticas ou não, constitui a concepção foucaultiana de dispositivo e, por sua vez, leva uma sociedade a discernir o que é certo ou errado na inscrição de suas verdades.

A partir desse entendimento, Gilles Deleuze (1990, p. 155-7) define o dispositivo como uma espécie de novelo, ou melhor, um conjunto multilinear composto por linhas de naturezas diferentes que não abrangem nem delimitam "[...] sistemas homogêneos por sua própria conta (o objeto, o sujeito, a linguagem), mas seguem direções diferentes, formam processos sempre em desequilíbrio, e essas linhas tanto se aproximam como se afastam uma das outras".

Deleuze (1990), desdobrando a ideia de dispositivo de Foucault, aponta ainda três dimensões: as curvas de visibilidade, as curvas de enunciação e as linhas de forças. O autor compara as duas primeiras com as máquinas de Raymond Roussel ${ }^{3}$, máquinas de fazer ver e de fazer falar. Ele afirma que a curva de visibilidade:

[...] não se refere a uma luz em geral que ilumina objetos pré-existentes; ela é feita de linhas de luz que formam figuras variáveis e inseparáveis deste ou daquele dispositivo. Cada dispositivo tem o seu regime de luz, a forma como esta cai, se esvai, se difunde, distribuindo o visível e o invisível, para fazer nascer ou desaparecer o objeto que não existe sem ela. (DELEUZE, 1990, p. 155, tradução nossa)

Com isso, entendemos que as curvas de visibilidades não são formadas pelos objetos pré-existentes, elas não são elementos concretos ou palpáveis, são mecanismos que se combinam entre o visível e o invisível, entre palavras, frases e proposições que se entrecruzam e dão possibilidades de existência, fazendo os sujeitos verem aquilo que está inscrito nos discursos.

Sobre as curvas de enunciação, Deleuze (1990, p. 155-6, tradução nossa) pontua:

\footnotetext{
${ }^{2}$ Esse texto foi suprimido da versão brasileira de Ditos e Escritos III, traduzida por Manoel Barros da Motta.

${ }^{3}$ Raymond Roussel (1877-1933), escritor francês, ficou conhecido pelo jogo linguístico, muitas das vezes enigmático, e pela criação de máquinas fantásticas presentes em suas obras.
} 
[...] as [curvas de] enunciações, por sua vez, remetem a linhas de enunciação em que se distribuem as posições diferenciais dos seus elementos; e, se as curvas são elas próprias enunciações, as são porque as enunciações são curvas que distribuem variáveis e porque uma ciência, em um determinado momento, ou um gênero literário, ou um estado de direito, ou um movimento social, se define precisamente pelos regimes de enunciação.

As curvas de enunciação permitem que práticas discursivas sejam materializadas e possibilitam a construção de objetos discursivos. Isso nos leva a crer que as curvas de enunciação não são, somente, aquilo que se fala sobre os sujeitos e sobre os elementos religiosos presentes nas práticas de Marabaixo, mas aquilo que se torna possível e justificável de ser dito acerca do universo que envolve o Ciclo do Marabaixo e a construção do sujeito negro.

O último elemento que compõe o dispositivo, de acordo com as leituras feitas por Deleuze (1990, p. 156, tradução nossa) acerca dos escritos de Foucault, corresponde às linhas de força:

Em terceiro lugar, um dispositivo implica linhas de forças. Parece que estas foram de um ponto singular a outro, situadas nas linhas precedentes; de alguma forma elas "retificam" as curvas anteriores, delineiam tangentes, envolvem os caminhos de uma linha com outra, operaram idas e vindas entre o ver e o dizer e vice-versa, atuando como setas que não cessam de penetrar as palavras e as coisas, que não param de travar uma batalha. A linha de força ocorre "em cada relação de um ponto com outro" e passa por todos os lugares de um dispositivo. Invisível e indizível, essa linha está intimamente misturada com as outras e, ainda assim, não pode ser distinguida. É a linha que corresponde a Foucault e cuja trajetória ele redescobre também Roussel, em Brisset, nos pintores Magritte e Rebeyrolle. Trata-se da "dimensão do poder", e o poder é a terceira dimensão do espaço interno do dispositivo, espaço variável com os dispositivos. Essa dimensão se compõe, assim como o poder, com saber.

As linhas de forças equivalem à dimensão do poder que envolve o dispositivo. O exercício de poder, operado pelos discursos inscritos no dispositivo religioso cristão, pode ser exercido pelas instituições Igreja, Estado, mídia, corpo social, bem como pelos sujeitos negros do Marabaixo, pois a linha de força ocorre no ponto de encontro de uma força com outra e passa por todos os espaços do dispositivo.

Sobre a dimensão do poder, Foucault (2015, p. 104) afirma que “[...] onde há poder, há resistência”, assim todo o jogo de força que incide sobre os sujeitos ou sobre o corpo social reage como um exercício de poder de resistência, caso contrário, afirma o filósofo, trataria simplesmente de questão de obediência. Dessa forma, o exercício de resistência também opera modos de contracondutas.

Em relação a isso, Deleuze (1990) ainda afirma que a dimensão do poder se compõe por saber. Seguindo esse entendimento, Veyne (2011) pontua que o dispositivo é o espaço em que o saber se cruza com o poder e coloca em funcionamento uma maquinaria discursiva que congrega jogos de força. Na tentativa de precisar suas relações mútuas, o autor assevera:

Na realidade, o saber é desinteressado, livre de todo poder, o Sábio está nas antípodas do Político, por quem só tem desprezo. Na realidade, o saber é frequentemente utilizado pelo poder, que frequentemente lhe presta seu auxílio. Bem entendido, não se trata de erigir o Saber e o Poder como uma espécie de casal infernal, mas de precisar a cada caso quais foram suas relações e, em primeiro lugar, se as tiveram, em por que vias. Quando as têm, eles se veem num mesmo dispositivo e se auxiliam mutuamente, uma vez que o poder é sábio em seu próprio domínio, o que dá poder a certos saberes. (VEYNE, 2011, p. 55)

O dispositivo mistura coisas e ideias (como a de verdade), representações, doutrinas e filosofias, com instituições, práticas sociais, econômicas, políticas (VEYNE, 2011). Com isso, o poder se faz de saber e, por meio das práticas discursivas, inscreve verdades dentro de um dispositivo que, por sua vez, faz funcionar jogos de forças (poder e resistência), produz imagens e modos de subjetivação.

A partir das discussões aqui apresentadas sobre a noção de dispositivo, circunscrevemos o dispositivo religioso cristão como toda uma maquinaria que submerge discursos verbais ou não e suas relações, como leis, normas, processos políticos que envolvem relações de poder, de saber e de hierarquia, que levam os sujeitos a partilhar um campo associado de práticas discursivas, a construir 
suas verdades, a produzir imagens e a constituir sujeitos. Consideramos as práticas festivas católicas em devoção à Santíssima Trindade e ao Divino Espírito Santo, as práticas festivas do Marabaixo que envolvem elementos como santos, santas, padres e todo uma rede de discursos envolvendo feras, instituição Igreja, feitiçaria, macumba, festa profana, cantigas populares religiosas, adereços, tambores, vestimentas, bebida alcoólica (gengibirra) etc., como práticas discursivas inscritas e maquinadas pelo dispositivo religioso cristão que estão em regime de (in)visibilidade ${ }^{4}$.

\section{PODER E RESISTÊNCIA ENTRE A IGREJA CATÓLICA E OS SUJEITOS NEGROS DO MARABAIXO NOS SÉCULOS XIX E XX}

Nesta seção, tratamos de descrever e interpretar práticas discursivas que sinalizam os conflitos entre a Igreja Católica e os sujeitos negros do Ciclo do Marabaixo. Com isso, selecionamos discursos que colocam em visibilidade os confrontos entre as práticas da Igreja e, ao mesmo tempo, as práticas dos sujeitos negros como processos de resistência. Veremos um conjunto de práticas da Igreja Católica que procurou deslegitimar e apagar os rituais do Marabaixo, bem como as práticas de resistência dos negros a esse movimento.

Sob tal direção, fizemos um recorte de uma crônica de Pancrácio Júnior, publicada na edição de 31 de maio de 1899 do jornal Pinsonia. Nesse texto, o autor registrou satiricamente os acontecimentos envolvendo atritos entre um religioso e as práticas do Ciclo do Marabaixo de Macapá daquele ano. Vejamos um recorte dessa crônica expresso na Sequência Discursiva (doravante SD) 01 :

SD 01:

[...] No decorrente anno, exerceu as funções de Juiz da festa o illustrado Sr. Dr. Alvares da Costa, que soube e poude talvez satisfazer aos mais exigentes, e é à espectativa dos devotos: foi todo amabilidade para com todos. Entretanto foi sensivel, para maior explendor, a ausencia do Sacerdote nas solenidades da egreja; falta esta que está desculpado o Sr. Juiz, que providenciou no sentido contrário, contractando para tal fim, como o Sr. Conego Teixeira, que vinha munido de uma portaria do governo bispado. Não sabemos o poderoso motivo que obstou, em caminho, bem próximo, a que o Sr. Conego Teixeira, tivesse faltado a tão sério compromisso. [...] No domingo da festa, em vez da patriarcal missa cantada (quantas pragas, Sr. Conego Teixeira...) houve grande ladainha à instrumental. A egreja não tinha um lugar vazio. [...] Do meio-dia em diante, grande parte do povo affluio a casa do Sr. Juiz, onde grande almoço ajantarado estava a disposição de quem o quis (PACRÁCIO JÚNIOR, 1899, grifos do autor apud CANTO, 1998, p. 21-25) 5 .

O Cônego Teixeira, figura religiosa, foi nomeado pela Igreja Católica para coordenar a festa na Catedral de São José de Macapá do ano de 1899. Contudo, no dia do evento, o religioso não compareceu, pois se tratava do acontecimento tradicional do Marabaixo dentro da igreja de São José. A recusa do padre foi uma forma de discursivizar a respeito dos sujeitos negros e do Ciclo do Marabaixo, bem como de colocar em visibilidade o exercício de poder da Igreja na tentativa de silenciar as práticas dos negros dentro dos rituais religiosos católicos. De acordo com Foucault (2011), as interdições, que atingem o discurso, revelam logo sua ligação com o desejo e com o poder, bem como suscitam novos discursos. Então, os exercícios de poderes que lançaram interdições sobre as práticas dos sujeitos negros, aqui também tratadas como processos de silenciamento, não tiveram um efeito de omissão e de apagamento por completo, visto que estar em silêncio é, também, resistir, é produzir dizeres. Portanto, ao mesmo tempo em que o padre silenciava o Ciclo com sua ausência, outros discursos eram produzidos, como o(s) discurso(s) da/pela crônica de Pancrácio, como as próprias ações dos sujeitos em driblar esse jogo de força.

O recorte da crônica (SD 01) faz o registro do andamento da festa sem a presença da autoridade religiosa do Cônego Teixeira. Diante disso, o Juiz da comarca de Macapá assumiu de última hora a coordenação dos festejos do Marabaixo. A ausência do religioso não intimidou os sujeitos negros praticantes do Marabaixo, pois, de acordo com a SD 01, "No domingo da festa, em vez da patriarcal

\footnotetext{
${ }^{4}$ Empregamos esse termo pelas leituras realizadas nos escritos de Deleuze (1990) acerca do dispositivo, pois, segundo o autor, o dispositivo possui um regime de luz o qual agencia o visível e o invisível, isto é, o regime de (in)visibilidade, possibilitando a existência do objeto discursivo.

${ }^{5}$ Sinalizamos que o texto é de 1899 , logo as palavras estão grafadas na língua portuguesa da época, diferenciando-se da língua portuguesa atual.
} 
missa cantada [...] houve grande ladainha à instrumental. A egreja não tinha um lugar vazio”. Com isso, segundo Deleuze (1990), temos dois movimentos de força ao se referir ao exercício de poder dentro de um dispositivo, ou seja, a linha de força ocorre no ponto de encontro de uma força com outra. Desse modo, as ações dos sujeitos negros em continuarem na igreja de São José de Macapá e de substituir a missa, devido à ausência do padre, por ladainhas, foram práticas de resistência contra o exercício repressor da Igreja Católica.

Outra sequência discursiva que descreve os atritos entre as práticas da Igreja com as práticas dos sujeitos negros diz respeito aos discursos de Zacarias Leite nas primeiras décadas do século XX. Zacarias Leite foi aluno do padre belga Júlio Maria Lombaerd, vigário da paróquia de São José de Macapá entre 1916 e 1926. Na localidade, Lombaerd era considerado professor, médico, farmacêutico, dentista e vigário (CANTO, 1998). Os ditos de Zacarias inscrevem conflitos travados entre as autoridades religiosas e os sujeitos negros do Marabaixo.
SD 02
Pe. Júlio combatia as festas do Marabaixo. Elas não passavam de batuque e bebedeira, com exploração de dinheiro, mediante a apresentação da coroa de prata do Espírito Santo conhecido como Divino. Pe. Júlio fechava a igreja mas o povo fincava o mastros na frente da matriz.
Era tradicional em Macapá deixar-se essa coroa do Divino na igreja de São José, de um dia para o outro. No dia seguinte, após a bênção dada pelo vigário, a cora era recolhida pelo festeiro, entre orgias populares.
P. Júlio não aceitava esse costume. Combatia-o publicamente. Um ano, na igreja, quebrou a cora de prata do divino e mandou entregar aos pedaços ao festeiro do Marabaixo.
O povo se revoltou e quis invadir a casa do Pe. Júlio. O Intendente, Cel. Teodoro Manuel Mendes (Prefeito), vendo a intenção geral, impediu que isso acontecesse, aconselhando o povo a se afastar da casa do vigário.
Nós alunos maiores, estávamos na casa paroquial armados de faca, rifles, cacetes, a fim de defender Pe. Júlio Maria, que permanecia sereno. Afinal tudo não passou de coisa momentânea (LEITE [entre 1916 e 1926] apud CANTO, 1998, p. 26-27, grifos do autor).

Nos dizeres "Pe. Júlio combatia as festas do Marabaixo" e "P. Júlio não aceitava esse costume. Combatia-o publicamente", temos enunciados que expressam a posição e o exercício de poder da Igreja frente às práticas dos sujeitos negros em um período conflitante que culminou, no final da primeira metade do século XX, com o fechamento das portas da igreja de São José para os sujeitos negros praticantes de Marabaixo.

Os discursos de Zacarias, que possivelmente reproduziam o pensamento de padre Júlio, categorizam as práticas de Marabaixo como "batuque e bebedeira, com exploração de dinheiro, mediante a apresentação da coroa de prata do Espírito Santo conhecido como Divino" (SD 02). Como tentativa de proibir tais práticas, padre Júlio, em determinado ano, "quebrou a cora de prata do Divino e mandou entregar aos pedaços ao festeiro do Marabaixo". A coroa era um objeto ligado às práticas cristãs, ela correspondia à coroa do Divino Espírito Santo. De igual forma, na atualidade, em Belém, no estado do Pará, os católicos cultuam o Círio de Nazaré, em que o ápice das práticas religiosas dessa festa corresponde à apresentação do "manto" da imagem de Nossa Senhora de Nazaré. No caso do Marabaixo, por ser praticado por grupos minoritários negros, a coroa do Divino funcionou como um mecanismo de subjetivação das práticas de Marabaixo, incomodando a Igreja que, em seu exercício de poder, subverteu seu próprio símbolo para coibir as práticas dos sujeitos negros.

Esse fato histórico provocou a revolta dos sujeitos negros, configurando-se como um processo de resistência contra as ações da Igreja. Isso visibiliza o exercício de poder da Igreja em impedir as práticas de Marabaixo. Além disso, na SD 02, também é possível sinalizar a aliança entre Estado e Igreja, pois, nos dizeres de Leite, o sujeito prefeito de Macapá interviu em prol da Igreja "aconselhando o povo a se afastar da casa do vigário".

Retomando a ideia de dispositivo como um conjunto de elementos heterogêneos que, nas suas relações, constituem uma rede de práticas (FOUCAULT, 1977), entendemos que as SD 01 e 02 trazem práticas discursivas com dois movimentos de forças operantes. De um lado, tem-se o exercício de poder da Igreja que procura eliminar as práticas de Marabaixo; na contramão, têm-se as práticas 
dos sujeitos negros que resistiam ao jogo de força daquela instituição. Um jogo de força isomórfico, inscrito por práticas discursivas de um dispositivo religioso cristão que operou como modo de exclusão das práticas de Marabaixo e como processo de subjetivação dos negros.

Considerando os atritos existentes entre Igreja e sujeitos negros praticantes do Marabaixo, destacamos um acontecimento que ficou marcado na historicidade desses negros. Como anunciado acima, na década de 1940, a Igreja intensificou os conflitos com os praticantes de Marabaixo e isso pode ter contribuído para o enfraquecimento do Ciclo. De acordo com Canto (1998, p. 32), a Igreja Católica tentou negar, na medida do possível, os elementos de religiões de matrizes africanas no Marabaixo, bem como "[...] os valores culturais africanos através de um discurso moralista e ideológico", na tentativa de silenciar a cultura religiosa africana e de preservar a doutrina cristã.

No fio do discurso, esse fato resultou na produção de discursos que proibiam as manifestações do Ciclo do Marabaixo dentro da igreja de São José de Macapá. De acordo com Alves et al. (2014, p. 59), nessa ocasião, o padre Júlio Maria Lombaerd, falando de um lugar institucional religioso, produziu dizeres que considerava o Ciclo como profano e imoral, culminando com o acontecimento de fechamento das portas da igreja para os praticantes de Marabaixo.

Fizemos um recorte de uma sequência discursiva da segunda metade do século XX, em que um sujeito negro do Marabaixo, Martinho Ramos, filho de Mestre Julião, o qual foi o líder negro do bairro Laguinho, relata o exercício de poder da Igreja, oriundo do acontecimento de fechamento das portas da igreja de São José de Macapá para os praticantes de Marabaixo.

SD 03:

Até 1948 tudo ia muito bem. Mas depois que os padres chegaram aqui (em Macapá) entenderam que o marabaixo era macumba, aí houve uma grande queda, mas ele [Julião] aguentou... (RAMOS, 1985 apud CANTO, 1998, p. 29, grifos do autor).

O acontecimento sob análise corresponde ao exercício de poder da Igreja em tentar silenciar e apagar as práticas dos sujeitos negros, ao mesmo tempo em que objetivava esses indivíduos. A Igreja manteve uma direta segregação das práticas discursivo-ritualísticas dos sujeitos negros até o ano de 2013, quando reabriu as portas da igreja para os sujeitos do Marabaixo. Na SD 03, há uma performance verbal que procura circunscrever as práticas do Marabaixo como macumba e, como resultado desses dizeres, há o relato de "grande queda" nas práticas do Marabaixo. A objetivação das práticas dos sujeitos negros do Marabaixo não se limita a discursos individuais, pelo contrário, essas práticas são colocadas em um universo profano e insano em que se imbricam outros rituais de sujeitos negros que foram marginalizados, como o Candomblé e a Umbanda no Brasil, bem como o Vodu no Haiti (TARTAGLIA, 2014). Os dizeres lançados sobre as práticas do Ciclo resultaram numa queda dos rituais dos sujeitos negros do Marabaixo, e isso demonstra o exercício de poder da Igreja em apagar as práticas desses sujeitos.

Destacamos outra sequência discursiva de Martinho Ramos:

SD 04

Tanto que ele [Julião] pertencia a irmandade do Sagrado Coração de Jesus e foi tirada a fita dele, então ele não pôde mais tomar parte da irmandade (RAMOS, 1985 apud CANTO, 1998, p. 29, grifos do autor).

O sujeito negro, Julião Ramos (Mestre Julião), geria o Marabaixo do bairro Laguinho e uma das ações repressoras da Igreja Católica foi a de retirar a sua fita da irmandade do Sagrado Coração de Jesus. Essa fita se configura como uma espécie de credenciamento entre fiéis católicos e algumas práticas do catolicismo. A retirada da fita foi um exercício de poder da Igreja contra os sujeitos negros e suas práticas de Marabaixo, uma vez que, sem a fita, Julião perderia o poder que a Igreja lhe conferia como membro de sua irmandade e, talvez, isso resultasse no apagamento das práticas dos sujeitos negros.

Considerando que o poder se exerce e que os sujeitos operam sobre sujeitos, temos o entendimento da existência de sujeitos ativos que exercem poderes. Nessa perspectiva, os sujeitos negros do Marabaixo também exerceram poderes sobre as práticas de 
silenciamento da Igreja. Como exemplo, destacamos o acontecimento pelo qual a Igreja Católica proibiu o Ciclo do Marabaixo no interior das instalações religiosas. Os sujeitos negros mantiveram seus rituais naquilo que se configurou como Marabaixo de Rua, mas não adentravam a igreja de São José. Na SD 03, temos os dizeres de que “houve uma grande queda, mas ele (Julião) aguentou...", o que indica que as ações dos sujeitos, mais uma vez, circunscrevem um exercício de poder contra as práticas repressoras da Igreja. Ainda em torno do acontecimento de fechamento das portas da igreja, destacamos a próxima sequência discursiva.

\begin{abstract}
SD 05
Assim, que por volta de 1950 deixaram de fincar os mastros em frente a igreja matriz para serem colocadas frente à casa dos festeiros. Após a morte de Julião Ramos (1958) a Sociedade do marabaixo, composta por mordomos e novenários desapareceu. Hoje raramente alguém (do sexo masculino) arrisca-se a jogar uma passos da "carioca" 6 num salão, sob o ritmo do "dobrado"7 ou da "galinha choca", como era chamada antes. As ladainhas e folias reduziram-se às novenas e é muito raro se servir rosquilhas de carimã, chocolate, pão-de-ló ou mesmo a famosa "mucura" agora substituída pela "gengibirra" (batida de gengibre). Enfim, quase tudo mudou (CANTO, 1998, p. 30)
\end{abstract}

Na sequência discursiva anterior, também temos dizeres que apontam para a resistência dos sujeitos negros ao exercício de poder da Igreja. Os negros foram proibidos de entrar na igreja com as práticas de Marabaixo, mas continuaram com o Marabaixo de Rua até a frente da igreja de São José de Macapá. Foram impedidos de fincar os mastros com a bandeira do Divino Espírito Santo e da Santíssima Trindade na frente da igreja, mas passaram a fixar os mastros na frente das casas dos festeiros. Essa relação de força está estritamente ligada à espacialidade, melhor dizendo, à construção de lugares outros.

Foucault (2013) pondera que cada grupo humano, qualquer que seja, demarca lugares utópicos no espaço que ocupa, onde realmente vive ou onde trabalha. De acordo com o filósofo, a sociedade é heterotópica. Ela constitui as suas heterotopias de formas extraordinariamente variadas. O Ciclo do Marabaixo urbano de Macapá também se configura como heterotopia. Exemplos disso são: a igreja de São José de Macapá, lugar legitimado pelo catolicismo; as ruas, por onde os sujeitos negros mantiveram e resistiram com o Ciclo do Marabaixo, as quais se constituíram em um novo espaço fortalecido pela resistência às proibições da Igreja (ver Frame 01); e as casas dos festeiros, que se transformaram nos barracões, lugares outros que abriga(ra)m a parte das festas de Marabaixo discursivizada como profana.

\footnotetext{
${ }^{6}$ Espécie de dança/luta semelhante à capoeira baiana.

${ }^{7}$ Parte mais ritmada dos sons dos tambores do Marabaixo.

${ }^{8}$ Segundo Nunes Pereira (1989), era uma bebida temperada com cachaça, ovos batidos e casquinhas de limão.
} 


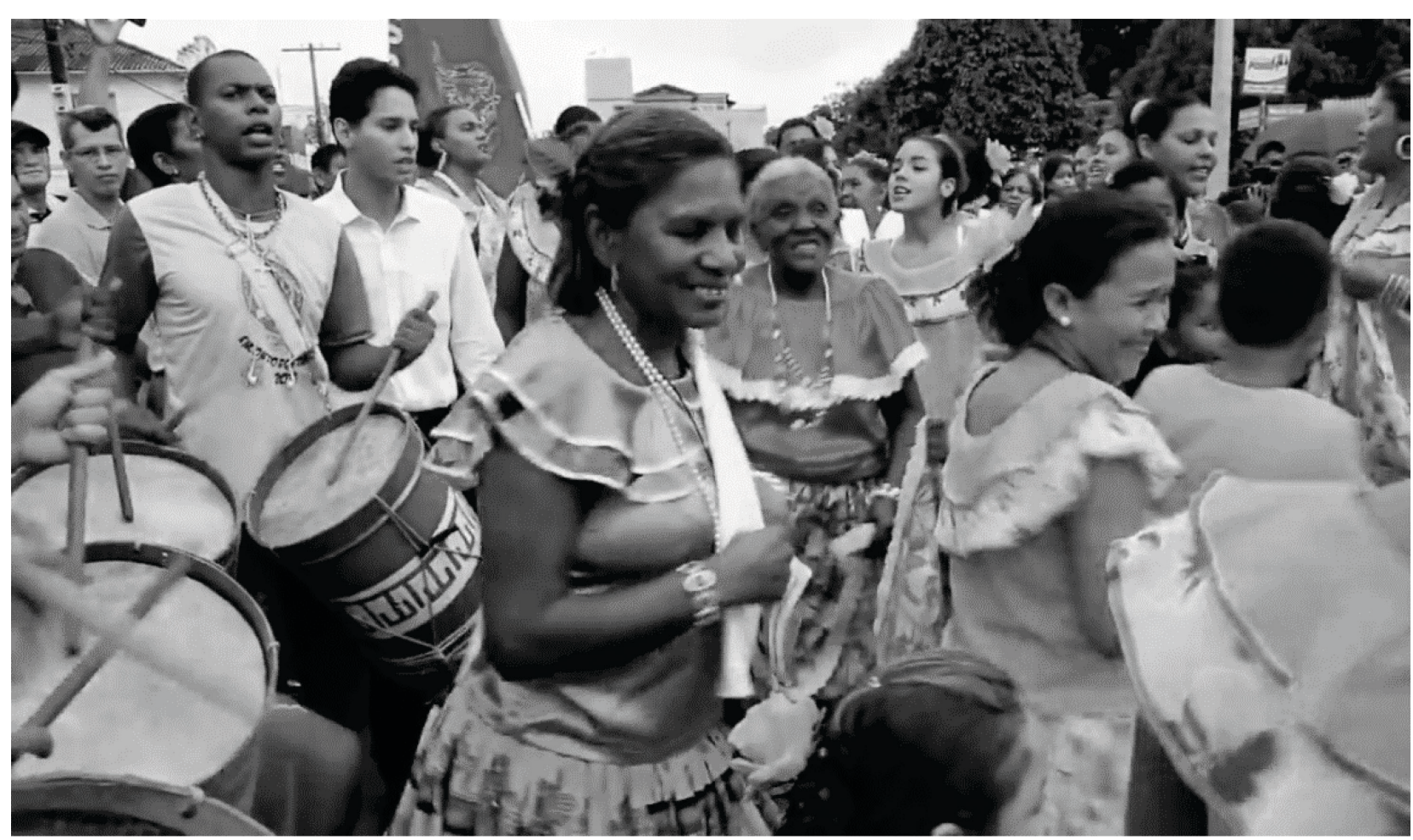

Frame 01: Marabaixo nas ruas de Macapá

Fonte: PESQUISA... (2017)

Os lugares das práticas de Marabaixo (acreditamos que não há um espaço específico, mas sim vários espaços, visto que o Marabaixo também acontece em outros municípios do Amapá, bem como o Ciclo do Marabaixo urbano de Macapá se desdobra em espaços já citados, como a igreja, as ruas, as casas dos festeiros etc.) são contraespaços (re)constituídos pelas lapidações do exercício de poder da Igreja Católica, do Estado, da sociedade macapaense etc., visto que as heterotopias, de acordo com Foucault (2013), são líquidas, constituem-se e se dissolvem. Em nosso recorte analítico, os lugares foram reconfigurados pelos exercícios de poder da Igreja, pois levaram os sujeitos negros a vivenciar as dobras do poder, sendo silenciados, enfraquecidos e subdivididos em alguns momentos. Por outro lado, esses espaços heterotópicos, criados como exercício de poder e de resistência contra a hegemonia da Igreja, levaram os negros a se reconhecerem como sujeitos do Marabaixo, fortalecendo essas práticas, institucionalizando-as.

\section{O ACONTECIMENTO DE 2013 COMO EFEITO DE RESISTENCIA DOS SUJEITOS NEGROS DO CICLO DO MARABAIXO}

Para Foucault (2005), existem vários níveis de acontecimentos, uns estão visíveis e podem ser classificados como de maior amplitude, outros invisíveis e podem ter uma dimensão menor, mas não com grau inferior de importância. Desse modo, o acontecimento de 2013 corresponde à reabertura das portas da igreja de São José de Macapá para o Ciclo do Marabaixo e toma uma proporção maior, é o grande acontecimento do século XXI, pois, desde a metade do século passado, os sujeitos negros praticantes do Marabaixo lutavam e aguardavam a reabertura das portas da igreja de São José para o Ciclo. Esse acontecimento sinaliza um marco delimitador nas lutas travadas entre a Igreja e os sujeitos negros, pois, considerando os processos de resistência desses sujeitos, ao longo da historicidade do Marabaixo, se inscreve como possibilidade de condutas, de reações e de modos de comportamentos que foram de encontro com as forças da Igreja. Na Figura 01, temos os sujeitos negros tocando as caixas (tambores) e dançando na frente da igreja de São José de Macapá. 


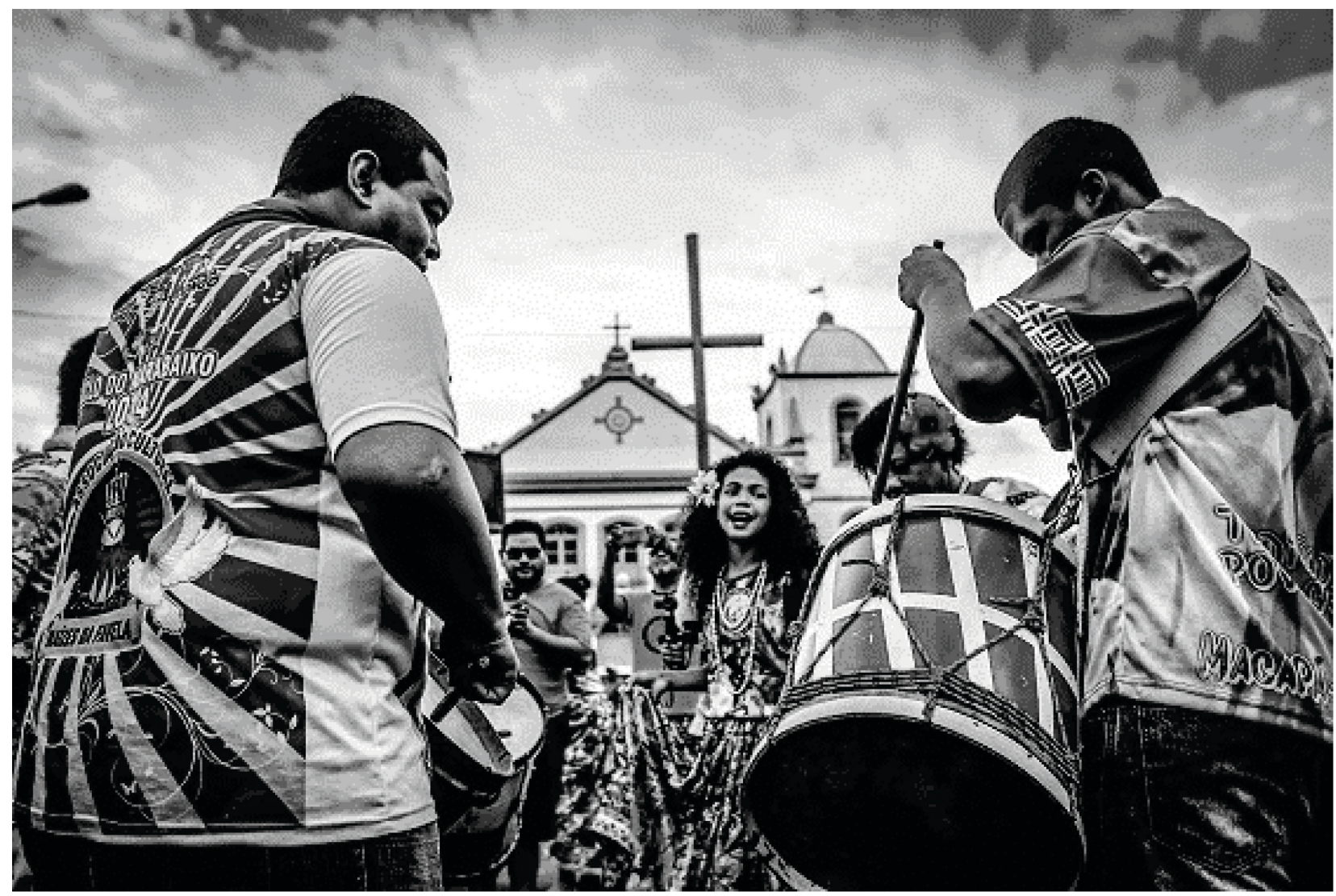

Figura 01: Sujeitos negros dançando o Marabaixo na frente da igreja de São José

Fonte: CICLO... (2017)

A fim de compreender como as relações de poder atuam por meio de redes de práticas discursivas e, nesse caso, colocando em jogo o dispositivo religioso cristão, fizemos um recorte de uma entrevista do Jornal Amapá TV (Telejornal da TV Amapá, afiliada da Rede Globo de televisão), o qual fez a cobertura do acontecimento de 2013.

\section{SD 06}

Jornalista - O sorriso no rosto, o colorido das roupas e a simpatia dos grupos tradicionais disfarçam um episódio do passado que há vários anos incomodam. O Marabaixo é tão antigo quanto a igreja matriz ${ }^{9}$. E os arredores da igreja foram durante anos palco desta festa que homenageia a Santíssima Trindade. Mas em um dado momento, as portas da matriz ficam fechadas para o Marabaixo (APTV..., 2013).

Os jogos discursivos inscritos nas orações "disfarçam um episódio do passado que há vários anos incomodam" e "Mas em um dado momento, as portas da matriz ficam fechadas para o Marabaixo” são tentativas de minimizar as ações da Igreja com relação aos sujeitos negros. Aqui, temos uma maquinaria discursiva capaz de dissimular propósitos em textos. Ela estabelece uma relação de saber e de poder ligada aos atritos existentes entre Igreja e sujeitos negros do Marabaixo. Na primeira oração, temos um episódio que incomoda(ou), mas que não pode ser dito. Na segunda, temos a personificação das portas da igreja, pois o discurso conduz a uma troca de posições: não foi a Igreja, com o exercício de dominação, que tentou silenciar os sujeitos do Ciclo do Marabaixo, mas é colocado como se as portas fossem o sujeito da ação, absolvendo a real Instituição responsável pela proibição das práticas dos sujeitos negros nas dependências da igreja de São José de Macapá, isto é, a própria Igreja Católica.

Transcrevemos outra sequência discursiva da reportagem televisiva de 2013. Em meio aos dizeres da reportagem, temos a sequência discursiva de Padre Lourenço Filho:

${ }^{9}$ A igreja matriz de São José de Macapá foi inaugurada em março de 1761. 


\section{SD 07}

Lourenço Filho (Padre): - Hoje é um dia que a gente está festejando, celebrando a entrada da coroa, a benção das murtas. Ea gente tem que ser uma Igreja que saiba dialogar, aproveitar os elementos essenciais da cultura amapaense. A Igreja não pode se impor de tal maneira, sem respeitar a tradição... as tradições do povo. E o Marabaixo é uma das maiores expressões culturais que o povo amapaense tem. Então, de certa forma, menosprezar isso, é menosprezar a história, é menosprezar seu próprio povo, é perder a essência da sua própria cultura (APTV ..., 2013, grifos nossos).

A reabertura das portas da igreja consistia em um acontecimento há anos aguardado pelos sujeitos negros, visto que a Igreja Católica havia proibido as práticas de Marabaixo dentro das instalações da igreja de São José. Na SD 07, temos o único momento da reportagem em que o sujeito padre se manifesta discursivamente. O discurso do sujeito representante religioso inicia com a afirmativa de comemoração à entrada da coroa do Divino Espírito Santo e à benção das murtas, trazendo, em seu interstício, uma aceitação duvidosa, pois não há o reconhecimento de uma ação negativa, no passado, por parte da Igreja em não aceitar as práticas discursivas e ritualísticas dos sujeitos negros do Ciclo do Marabaixo. Além disso, não há dizeres que correspondem a uma reabertura para as práticas dos negros do Marabaixo. De forma alusiva, pode-se tomar o entendimento de que comemorar a entrada da coroa do Divino e abençoar as murtas são práticas que possivelmente podem levar a Igreja a reconhecer o Marabaixo.

Para relacionar à SD 07, recortamos a SD 08 da página eletrônica do Santuário de Fátima do Amapá. Considerando que o Marabaixo se trata de práticas religiosas dentro do calendário litúrgico católico, a Igreja, na atualidade, tenta divulgá-lo, entretanto, sinalizamos um jogo discursivo que procura subverter os acontecimentos passados.

\section{SD 08}

Apenas no Laguinho o MARABAIXO sobrevive com grande parte de suas características do passado. Como fato folclórico modificou-se muito através do tempo, dado à variáveis como a urbanização, a modernização e a migração rural, como ocorreu em Mazagão Velho, no município de Mazagão e na localidade de Curiaú, à 8 Km de Macapá (MARABAIXO..., 2017, grifos nossos).

A SD 08 traz, em seus dizeres, possíveis motivos que teriam levado à perda dos caracteres do passado na estruturação espacial do Ciclo do Marabaixo. Podemos observar três acontecimentos. O primeiro diz respeito ao Bairro Laguinho (em Macapá), uma das localidades para as quais os sujeitos negros foram realocados no governo de Janary Nunes ${ }^{10}$. O segundo corresponde ao movimento ligado à comunidade de Mazagão Velho, constituída por famílias de negros transplantados do Marrocos para o interior do Amapá no século XVIII e, ao longo da história, parte desta comunidade migrou para Macapá e para o atual município de Mazagão. Já o Curiaú é, atualmente, reconhecido como comunidade quilombola e distrito de Macapá. O Curiaú serviu de reduto de escravos que fugiram da escravidão no período da construção da Fortaleza de São José de Macapá. Três acontecimentos históricos que passaram ao nível do discurso no que se refere à historicidade e espacialidade dos sujeitos negros amapaenses.

Ao observar o jogo discursivo expresso nas escolhas linguísticas do religioso na SD 07 e fazendo uma ligação com os discursos da SD 08, retirada da página eletrônica do Santuário de Fátima no Amapá, é possível observar apagamentos dos acontecimentos históricos exercidos pela Igreja contra as práticas dos sujeitos negros. Possivelmente, nos discursos do sujeito padre (SD 07), haveria a tentativa de dizer que a Igreja teria reconhecido parte dos conflitos travados com os sujeitos negros do Marabaixo no passado. Entretanto, com a SD 08, publicada em 2017, como vimos, as práticas da Igreja foram subvertidas pelos acontecimentos de urbanização e de migração. Tal exercício de poder expresso por meio do discurso dá proeminência a elementos discursivos que sustentam os dizeres de uma Igreja acolhedora em relação à diversidade cultural.

\footnotetext{
${ }^{10} \mathrm{Na}$ Era Vargas, o governo de Janary Nunes retirou os sujeitos negros do centro de Macapá e os realocou em bairros periféricos, motivado por um discurso de progresso e de urbanização da cidade.
} 


\section{CONSIDERAÇÕES FINAIS}

As discussões e análises aqui empreendidas colocam em visibilidade modos de existir e dadas formas de práticas de linguagem como lugares de exercício de poder e, também, de exercício de resistência. Assim, pensamos que o trabalho do analista do discurso, pautado nos estudos foucaultianos, é discutir e compreender os modos de vida de nossa sociedade.

Por meio desta análise, observamos o funcionamento de uma maquinaria discursiva inscrita em um dispositivo religioso cristão que fez poderes serem exercidos. Pelas curvas de visibilidade e de enunciação, a Igreja Católica fabricou um sujeito que possuía determinadas práticas que não se inscreviam no campo legitimado do catolicismo, sendo colocadas como marginais, profanas e imorais. Nesse processo, a Igreja, fazendo uso de seu exercício de poder, objetivou e desqualificou os sujeitos negros por terem práticas de origem africanas, ao mesmo tempo em que lançava sua hegemonia, em meio aos processos de interdição das práticas desses sujeitos.

Como salientou Foucault (2012), onde há poder também há resistência, assim, pontuamos que o nosso empreendimento analítico sinaliza as lutas sociais travadas, principalmente, entre os sujeitos negros do Marabaixo e a Igreja Católica, em práticas discursivas operadas por um dispositivo religioso cristão. Dispositivo que fez funcionar poderes deslegitimadores e exercícios de resistência que também constituía o sujeito negro do Ciclo do Marabaixo urbano de Macapá, no Amapá.

\section{REFERÊNCIAS}

AGAmbeN, G. O que é um dispositivo? Trad. Nilceia Valdati. Outra Travessia, Florianópolis, n. 5, p. 9-16, jul./dez. 2005.

ALVES, I. C.; LOBATO, L. G. R.; PEREIRA, M. L.; NOGUEIRA, R. S. O Ciclo do Marabaixo em Macapá e a Igreja Católica Romana. Journal of Bioenergy and Food Science, Macapá, v. 1, n. 2, p. 57-60, jul./set. 2014.

APTV: cortejo da murta do Marabaixo em Macapá. Macapá: Amapá TV, 29 jul. 2013. 1 vídeo (4:42 min). Disponível em: https: https://www.youtube.com/watch?v=fdBtIT c5qs . Acesso em: 25 maio 2017.

CANTO, F. A água benta e o diabo. 2. ed. Macapá: FUNDECAP, 1998.

CICLO do Marabaixo: a essência da cultura amapaense. Portal Governo do Estado do Amapá, Macapá, 15 abril 2017. Disponível em: https://portal.ap.gov.br/noticia/1504/ciclo-do-marabaixo-a-essencia-da-cultura-amapaense. Acesso em: 26 mai. 2017.

DELEUZE, G. ¿Que és un dispositivo? In: DELEUZE, G. Michel Foucault, filósofo. Barcelona: Gedisa, 1990. p. $155-161$.

FOUCAULT, M. “Le jeu de Michel Foucault. Entretien”. Ornicar? Bulletin périodique du champ freudien, n. 10, p. 62-93, jul. 1977.

FOUCAULT, M. Retornar à História. In: FOUCAULT, M. Arqueologia das ciências e história dos sistemas de pensamento. Ditos e Escritos II. MOTTA, M. B. (org.). Rio de Janeiro: Forense Universitária, 2005. p. 282-295.

FOUCAUlT, M. A ordem do discurso. Tradução Laura Fraga de Almeida Sampaio. 21. ed. São Paulo: Edições Loyola. 2011.

FOUCAULT, Michel. Microfísica do poder. 25. ed. São Paulo: Graal, 2012.

FOUCAULT, M. O corpo utópico, as heterotopias. Tradução Salma Tannus Muchail. São Paulo: N-1 Edições, 2013. 
FOUCAULT, M. História da sexualidade I: a vontade de saber. Tradução Maria Thereza da Costa Albuquerque e J. A. Guilhon Albuquerque. 3. ed. São Paulo: Paz e Terra, 2015.

MARABAIXO. Página oficial do Santuário de Fátima, Macapá, 14 fev. 2017 . Disponível em: http://santuariodefatimaoficial.com/2017/02/14/marabaixo/. Acesso em: 24 nov. 2017.

TARTAGLIA, E. Imigrantes haitianos: da dinâmica de saída à dinâmica de entrada. 2014. Dissertação (Mestrado em Letras) Programa de Pós-Graduação Mestrado Acadêmico em Letras, Universidade Federal de Rondônia, Porto Velho, 2014.

TARTAGLIA, E. Práticas de poder, de resistência e de subjetivação: os discursos dos/sobre os sujeitos negros do Ciclo do Marabaixo macapaense. Tese (Doutorado) - Programa de Pós-Graduação em Letras, Universidade Estadual de Maringá, Maringá, 2019.

VEYNE, P. Foucault: seu pensamento, sua pessoa. Tradução Marcelo Jacques de Morais. Rio de Janeiro: Civilização Brasileira, 2011. 